\title{
Modeling Study on Two-phase Adiabatic Expansion in a Reciprocating Expander
}

\author{
Hiroshi Kanno*and Naoki Shikazono** \\ *Railway Technical Research Institute, 2-8-38 Hikari-cho Kokubunji-shi, Tokyo, Japan \\ ** The University of Tokyo, 4-6-1 Komaba Meguro-ku, Tokyo, Japan
}

\begin{abstract}
In the present study, modeling of two-phase adiabatic expansion in a reciprocating cylinder is proposed. Experimental data obtained from the setup with piston and cylinder which mimics reciprocating expander were used for model validation. From the experiment, it is recognized that mixing of the liquid due to boiling bubbles has a strong impact on pressure change during adiabatic expansion. Therefore, two phase adiabatic vaporization in a cylinder is considered to be mainly dominated by the heat transfer between the bulk liquid and the gas-liquid interface. Experimental correlation for the Nusselt number based on Prandtl, Reynolds and Bond numbers is proposed. Pressure change and indicated adiabatic efficiency in adiabatic two phase expansion are calculated by solving the energy balance equations using the proposed Nusselt number correlation. The present model can reproduce the pressure-change and the indicated adiabatic efficiency in adiabatic two phase expansion within about $5 \%$ accuracy.
\end{abstract}

Keywords: Two-phase flow, Adiabatic expansion, Indicated adiabatic efficiency, Boiling, Heat transfer

\section{Introduction}

In recent years, wet vapor expansion and two-phase expansion are attracting large attentions in waste heat recovery systems from low to moderate temperature heat sources. In this field, organic Rankine cycles (ORCs) and trilateral cycle have been studied in order to improve the energy utilization efficiency [1-5]. By keeping the working fluid as a single liquid phase in the heat exchange process, the temperature profile matching between the working fluid and heat source is drastically improved, which results in low exergy loss of the cycle. Therefore, exergy efficiency of the trilateral cycle can be theoretically the highest among the other heat cycles when the heat source temperature descends during the heat exchange process. In the trilateral cycle, two phase expander is the key component of the system. From the view point of erosion durability, the volumetric expander is preferable to attain high reliability. It is very important to clarify the two-phase expansion phenomenon for the development of efficient and reliable two-phase expander.

To evaluate the potential of the trilateral cycle, knowledge on two phase expansion is indispensable. There are several experimental studies on wet-vapor expansion for Lysholm turbine expander. Smith et al. [6-8] estimated the performance and the cost of trilateral flash cycle using Lysholm twin screw turbine. Oreijah et al. [9] conducted an experimental study to compare trilateral flash cycle and ORC using screw expanders. They reported that the trilateral cycle has a potential for reaching larger thermal efficiency than conventional ORCs. Ohman et al. [10] investigated Lysholm turbine and reported that peak efficiency is sensitive to the inlet vapor condition. They also proposed an empirical correlation for the 
adiabatic efficiency, which assumes a linear relationship between vapor fraction and adiabatic efficiency [11].

When using a heat source of moderate temperature, the expansion ratio becomes very large in the trilateral cycle [1-2]. To overcome this difficulty, a reciprocating expander should be a preferable choice since it can be designed for large expansion ratio conditions. Bao et al. [12] reviewed the characteristics of different types of expenders. They evaluated the capacities, costs and advantages, and mentioned that the reciprocating piston expander has wide adaptability for variable working conditions and tolerance for two-phase expansion. Studies on two-phase expansion phenomenon in a cylinder (constant-volume chamber) are reported as flash expansion experiments in the field of refrigeration, desalination, nuclear reactor, jet nozzle or other chemical processes. Yan et al. [13] and Zhang et al. [14] carried out experiments on static and circulatory flash evaporation and investigated the steam-carrying effect. Saury et al. [15] studied flash evaporation of water film and proposed a correlation between the dimensionless maximum mass flow rate, dimensionless initial temperature, depressurization rate, superheat and initial water height.

The above flash evaporation studies were carried out in a flash chamber, but did not focus on the output work which could be taken out from the system. Studies on the pressure change and adiabatic efficiency in two-phase expansion are still limited, so further investigations on two-phase adiabatic expansion to increase output power and to improve adiabatic efficiency are needed. Especially, to clarify the phenomenon, modeling study on adiabatic two-phase expansion should be conducted. As intake and exhaust valves are located closely in the reciprocating expander, the hot liquid is introduced into the cold cylinder wall, which results in the heat capacity loss from the working fluid. Steffen et al. [16] simulated the performance of trilateral cycle using a reciprocating expander with cyclone separator, in which the saturated liquid working fluid is separated into liquid and vapor, and only vapor phase is introduced into the cylinder. They also evaluated the material of cyclone and reported that the effective thermal insulation of the cyclone wall is important. Therefore, thermal insulation or heat transfer from the working fluid to the cylinder wall will become important for the modeling study on the two-phase adiabatic expansion phenomenon.

In the present study, modeling of phase-change on the liquid-vapor interface in a reciprocating cylinder is proposed using our previous experimental results [17, 18]. An experimental correlation for the Nusselt number based on Prandtl, Reynolds and Bond numbers is proposed. Using the correlation, a model which can predict pressure change and indicated adiabatic efficiency during adiabatic two-phase expansion is developed. 


\begin{tabular}{|c|c|}
\hline \multicolumn{2}{|c|}{ NOMENCLATURE } \\
\hline Bo & Bond number \\
\hline$c$ & Heat capacity $[\mathrm{kJ} /(\mathrm{kg} \cdot \mathrm{K})]$, coefficient \\
\hline$c_{\mathrm{p}}$ & Liquid heat capacity $[\mathrm{kJ} /(\mathrm{kg} \cdot \mathrm{K})]$ \\
\hline$d$ & Diameter $[\mathrm{mm}]$ \\
\hline$D$ & Piston diameter $[\mathrm{mm}]$ \\
\hline E & Energy $[\mathrm{kJ}]$ \\
\hline$g$ & Gravity acceleration $\left[\mathrm{m} / \mathrm{s}^{2}\right]$ \\
\hline$h$ & Heat transfer coefficient $\left[\mathrm{W} /\left(\mathrm{m}^{2} \cdot \mathrm{K}\right)\right)$ \\
\hline $\mathrm{Ja}$ & Jacob number \\
\hline$L$ & Latent heat $[\mathrm{kJ} / \mathrm{kg}]$ \\
\hline$m$ & Mass $[\mathrm{kg}]$ \\
\hline $\mathrm{Nu}$ & Nusselt number \\
\hline$p$ & Pressure $[\mathrm{MPa}]$ \\
\hline $\mathrm{Pr}$ & Prandtl number \\
\hline$Q$ & Heat $[\mathrm{kJ}]$ \\
\hline Re & Reynolds number \\
\hline$t$ & Time $[\mathrm{s}]$ \\
\hline$S$ & Interface area $\left[\mathrm{m}^{2}\right]$ \\
\hline$T$ & Temperature $\left[{ }^{\circ} \mathrm{C}, \mathrm{K}\right]$ \\
\hline$u$ & Specific internal energy $[\mathrm{kJ} / \mathrm{kg}]$ \\
\hline$v$ & Velocity $[\mathrm{mm} / \mathrm{s}]$ \\
\hline$V$ & Volume $\left[\mathrm{m}^{3}\right]$ \\
\hline$W$ & Work $[\mathrm{kJ}]$ \\
\hline \multicolumn{2}{|c|}{ Greek symbols } \\
\hline$\alpha$ & Acceleration $\left[\mathrm{mm} / \mathrm{s}^{2}\right]$ \\
\hline$\varepsilon$ & Ratio \\
\hline$\Delta$ & Difference \\
\hline$\lambda$ & Thermal conductivity $[\mathrm{W} /(\mathrm{m} \cdot \mathrm{K})]$ \\
\hline$\mu$ & Viscosity $[\mathrm{Pa} \cdot \mathrm{s}]$ \\
\hline$\theta$ & Angle $[\mathrm{CA}]$ \\
\hline$\rho$ & Density $\left[\mathrm{kg} / \mathrm{m}^{3}\right]$ \\
\hline$\sigma$ & Surface tension $[\mathrm{mN} / \mathrm{m}]$ \\
\hline$\eta$ & Efficiency [\%] \\
\hline \multicolumn{2}{|c|}{ Subscripts } \\
\hline 0 & Initial condition \\
\hline $\mathrm{ad}$ & Adiabatic \\
\hline b & Bubble \\
\hline cut & Cut-off \\
\hline cyl & Cylinder \\
\hline $\exp$ & Expansion \\
\hline $\mathrm{fl}$ & Working fluid \\
\hline gen & Generated \\
\hline heat & Heat capacity \\
\hline inj & Injection(measured in inlet valve) \\
\hline int & Interface \\
\hline ise & Isentropic (quasi-static) \\
\hline Lap & Laplace \\
\hline 1 & Liquid \\
\hline loss & Loss \\
\hline $\mathrm{p}$ & Piston \\
\hline sat & Saturation \\
\hline SUS & Bottom stainless plate \\
\hline $\mathrm{v}$ & Vapor \\
\hline vol & Volume \\
\hline
\end{tabular}




\section{Heat transfer phenomena in two-phase expansion}

\subsection{Experimental setup}

Experimental setup is the same as our previous study $[17,18]$. The cylinder is a double pipe made of polycarbonate. The piston with diameter of $D_{\mathrm{p}}=55 \mathrm{~mm}$ is also made of polycarbonate. The bottom of the cylinder is made of thin stainless plate with thickness of $0.8 \mathrm{~mm}$.

In the experiment without intake and exhaust process, degassed working fluid is introduced into the cylinder, and the working fluid and the setup are heated up to operating temperature by hot air, and then the double tube is vacuumed by a vacuum pump for thermal insulation before the expansion experiment. The temperature of liquid and vapor phases are measured by thermocouples attached to the piston and the bottom of the cylinder. The pressure in the cylinder is measured by the pressure sensor embedded in the piston. Indicated work is obtained from a $P-V$ diagram.

In the experiment with intake and exhaust valves, water and ethanol are used as the working fluids, and their inlet temperatures $T_{\mathrm{inj}}$ are $100{ }^{\circ} \mathrm{C}$ and $80{ }^{\circ} \mathrm{C}$, respectively. In this setup, intake and exhaust valves are located at the bottom plate, so the bottom plate is cooled by the remained working fluid after the preceding exhaust process. In the subsequent expansion process, the introduced hot working fluid is cooled by the bottom plate. This heat capacity loss is not observed in the closed system without valves, and this loss is inherent for the case with intake and exhaust processes.

After 10 cycles of intake, expansion and exhaust processes as a warming-up operation, data for 5 cycles of intake, expansion and exhaust processes are collected for data acquisition. Temperature, pressure and piston displacement were measured. Output work is calculated by taking the average of 5 cycles of the $P-V$ diagram. Indicated adiabatic efficiency is also evaluated from the $P-V$ diagram. The details of the experimental procedures can be found in Refs. [17, $18]$.

Table 1 Physical properties of stainless plate and cylinder.

\begin{tabular}{ccc}
\hline & $\begin{array}{c}\text { Stainless plate } \\
\text { (SUS304) }\end{array}$ & $\begin{array}{c}\text { Cylinder } \\
\text { (polycarbonate) }\end{array}$ \\
\hline$\rho\left[\mathrm{kg} / \mathrm{m}^{3}\right]$ & 9790 & 1200 \\
$c[\mathrm{~kJ} /(\mathrm{kg} \cdot \mathrm{K}))$ & 0.59 & 1.05 \\
\hline
\end{tabular}

Table 2 Experimental condition in a closed cylinder without intake and exhaust processes [17].

\begin{tabular}{cc}
\hline Parameter & Range \\
\hline$T_{0}\left({ }^{\circ} \mathrm{C}\right)$ & $80-120$ \\
$z_{1}(\mathrm{~mm})$ & 6.0 \\
$z_{0}(\mathrm{~mm})$ & 9.0 \\
$r_{\exp }$ & 20 \\
$D_{\mathrm{p}}(\mathrm{mm})$ & $38,44,55$ \\
$a_{\mathrm{p}}\left(\mathrm{mm} / \mathrm{s}^{2}\right)$ & 833 \\
$v_{\mathrm{p}}(\mathrm{mm} / \mathrm{s})$ & $1-192$ \\
\hline
\end{tabular}


Table 3 Experimental condition in a cylinder with intake and exhaust processes [18].

\begin{tabular}{cc}
\hline Parameter & Value \\
\hline$z_{1}[\mathrm{~mm}]$ & 6.0 \\
$z_{0}[\mathrm{~mm}]$ & 0.5 \\
$z_{\max }[\mathrm{mm}]$ & 180 \\
$\alpha_{\mathrm{p}}\left[\mathrm{mm} / \mathrm{s}^{2}\right]$ & $10-769$ \\
$v_{\mathrm{p}, \max }[\mathrm{mm} / \mathrm{s}]$ & $42.4-371.6$ \\
$\varepsilon_{\text {cut, vol }}[\mathrm{mm} / \mathrm{s}]$ & $3-30$ \\
$\varepsilon_{\exp }[\mathrm{mm} / \mathrm{s}]$ & 30 \\
\hline
\end{tabular}

$$
\begin{gathered}
\varepsilon_{\text {cut,vol }}=\frac{V_{\text {cyl,cut }}}{V_{\text {pl,max }}} \\
\varepsilon_{\text {exp }}=\frac{V_{\text {cyl,max }}}{V_{\text {pl,max }}}
\end{gathered}
$$

\subsection{Heat transfer between liquid bulk and gas-liquid interface}

Figure 1 shows the schematic of the mean temperature profile in the cylinder assuming that evaporation from gasliquid interface dominates boiling during the phase change process. It is assumed that the gas-liquid interface and vapor temperatures are equal to the saturation temperature. In the two-phase adiabatic expansion, latent heat consumed by evaporation is supplied from the sensible heat of the liquid phase. Therefore, as shown in Fig. 1, a large temperature gradient will appear in the liquid phase. From this discussion, it is expected that the heat transfer from the liquid bulk to the gas-liquid interface is the dominant mechanism of adiabatic two phase expansion.

From the energy equation, latent heat of evaporation balances with the transferred heat from the liquid bulk as shown in Eq. (3). Assuming that gas phase is saturated, heat transfer coefficient $h_{\mathrm{l}-\mathrm{v}}$ in Eq. (4) can be estimated from the measured gas and liquid temperatures. As the interface temperature is assumed to be equal to the saturation temperature, the temperature difference in Eq. (3) can be written by the liquid bulk and saturation temperatures, as Eq. (4).

The physical properties and operating parameters related to this phenomenon are liquid thermal conductivity $\lambda_{\text {, liquid }}$ heat capacity $C p_{1}$, liquid and vapor densities $\rho_{\mathrm{l}}, \rho_{\mathrm{v}}$, vapor velocity at the interface $v_{\mathrm{v}}$, departure bubble diameter $d_{\mathrm{b}}$ and Laplace length $d_{\text {Lap. }}$. In pool boiling, Laplace length is widely used as a characteristic length [19 - 21], which is defined as Eq. (5). Normal component of the average vapor velocity $v_{\mathrm{v}}$ cannot be given a priori, but is determined as a result of the evaporation rate at the interface. Therefore, $v_{\mathrm{v}}$ is not a convenient input parameter for the correlation. On the other hand, as we assume that the interface temperature is equal to the saturated vapor temperature, generation of the saturated vapor can be estimated from the piston movement. Therefore, we use piston velocity as a representative of the vapor velocity in the present study.

By the dimensional analysis using $\pi$ theorem, Nusselt number is expressed as in the form of Eq. (6). In Eq.(6), Departure bubble diameter is calculated from the Cole's correlation [22 - 24] as shown in Eqs. (7) to (8), which can be applied to saturated pool boiling in atmospheric or sub-atmospheric pressure. Bond and Jacob numbers used in Eq. (8) are defined as Eqs. (7) and (9), respectively. In Cole's correlation, $B o^{1 / 2}$ is the dimensionless departure bubble diameter, and $J a$ is the ratio of sensible heat to latent heat absorbed during the liquid-vapor phase change.

The Nusselt number is expressed as the function of Prandtl, Reynolds, Bond numbers and density ratio between liquid and vapor phases. Coefficients in Eq. (6) are fitted as $c_{1}=18.2, c_{2}=0.58, c_{3}=0.987, c_{4}=0.77$ and $c_{5}=-0.4$ from the previous two-phase expansion experiments $[17,18]$, both with and without intake and exhaust processes. 
Figure 2 shows the measured Nusselt number and the calculated one by the correlation for water without intake and exhaust processes. At the beginning of the expansion, the Nusselt number shows a large peak because evaporation takes place with very small temperature difference. Then, Nusselt number gradually decreases due to the development of temperature distribution. Figure 3 shows the measured and correlated Nusselt numbers for water with intake and exhaust processes. At the early stage of expansion, the Nusselt number shows large peak as in the case without intake process. After the introduction of the working fluid, the Nusselt number gradually increases and then decreases because of Reynolds number change due to the piston speed change. Figure 4 shows the measured and correlated Nusselt numbers for ethanol with intake and exhaust processes. There is some difference between measured and calculated Nusselt numbers at the early stage of expansion process. In our experimental setup, compressed air is used to refill the working fluid into the plunger. It is considered that dissolved air in the working fluid is one of the causes of this difference.

As shown in the figures, proposed $N u$ correlation can reproduce the experimental results well for both with and without valves and for two working fluids. By using this correlation, the evaporation mass flow rate from the liquid to the vapor can be calculated.

The coefficients in Eq. (6) are obtained from the setup that mimics the reciprocating expander, so it is not clear whether the model can be applied for other types of expanders such as rotary expander. On the other hand, if temperature distribution in the liquid phase still dominates as the rate limiting process, we may expect that the present model will hold also in other types of expanders. In the model, characteristic velocity is used in Eq. (6). For the screw expander, characteristic velocity can be calculated from a product of the working room volume change per angle $\left(\mathrm{m}^{3} / \theta\right)$, rotational speed $(\theta / \mathrm{s})$ and the cross sectional area $\left(\mathrm{m}^{2}\right)$ between the rotor and the casing. However, the coefficients in Eq. (6) should be determined from the experiments of different expanders.

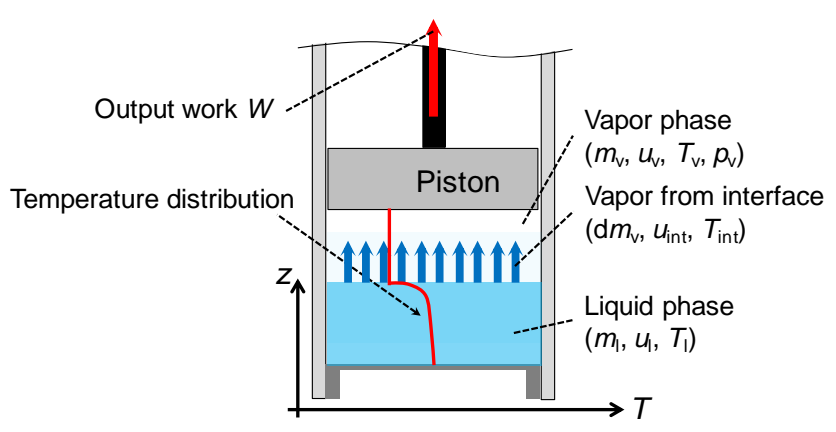

Fig. 1 Temperature gradient in the cylinder

$$
\begin{gathered}
\frac{\mathrm{d} m_{\mathrm{v}}}{\mathrm{d} t} L=S_{\mathrm{p}} h_{\mathrm{int}} \Delta T_{\mathrm{sat}} \\
\Delta T_{\mathrm{sat}}=T_{\mathrm{l}, \mathrm{bulk}}-T_{\mathrm{sat}}\left(p_{\mathrm{v}}\right) \\
d_{\text {Lap }}=\sqrt{\frac{\sigma_{\mathrm{l}}}{g\left(\rho_{\mathrm{l}}-\rho_{\mathrm{v}}\right)}}
\end{gathered}
$$




$$
\begin{gathered}
N u=\frac{h_{\text {int }} d_{\text {Lap }}}{\lambda_{1}} \\
=1+c_{1}\left(\frac{C p_{1} \mu_{1}}{\lambda_{1}}\right)^{c_{2}}\left(\frac{\rho_{1} v_{\mathrm{p}} d_{\text {Lap }}}{\mu_{\mathrm{l}}}\right)^{c_{3}}\left(\frac{\rho_{\mathrm{v}}}{\rho_{\mathrm{l}}}\right)^{c_{4}}\left(\frac{d_{\mathrm{b}}}{d_{\text {Lap }}}\right)^{c_{5}} \\
=1+c_{1}\left(\frac{v_{1}}{\frac{\lambda_{1}}{\rho_{\mathrm{l}} C p_{1}}}\right)^{c_{2}}\left(\frac{v_{\mathrm{p}} d_{\mathrm{Lap}}}{v_{1}}\right)^{c_{3}}\left(\frac{\rho_{\mathrm{v}}}{\rho_{\mathrm{l}}}\right)^{c_{4}}\left(\frac{d_{\mathrm{b}}}{d_{\mathrm{Lap}}}\right)^{c_{5}} \\
=1+c_{1} \operatorname{Pr}^{c_{2}} \operatorname{Re}_{\mathrm{v}}{ }^{c_{3}}\left(\frac{\rho_{\mathrm{v}}}{\rho_{\mathrm{l}}}\right)^{c_{4}} B o^{c_{5}} \\
c_{1}=18.2, c_{2}=0.58, c_{3}=0.987, c_{4}=0.77, c_{5}=-0.40 \\
B o=\frac{d_{b}{ }^{2} g\left(\rho_{1}-\rho_{\mathrm{v}}\right)}{\sigma_{1}} \\
B o^{\frac{1}{2}}=0.04 J a \\
J a=\frac{\rho_{1} C p_{1} \Delta T_{\mathrm{sat}}}{\rho_{\mathrm{v}} L}
\end{gathered}
$$




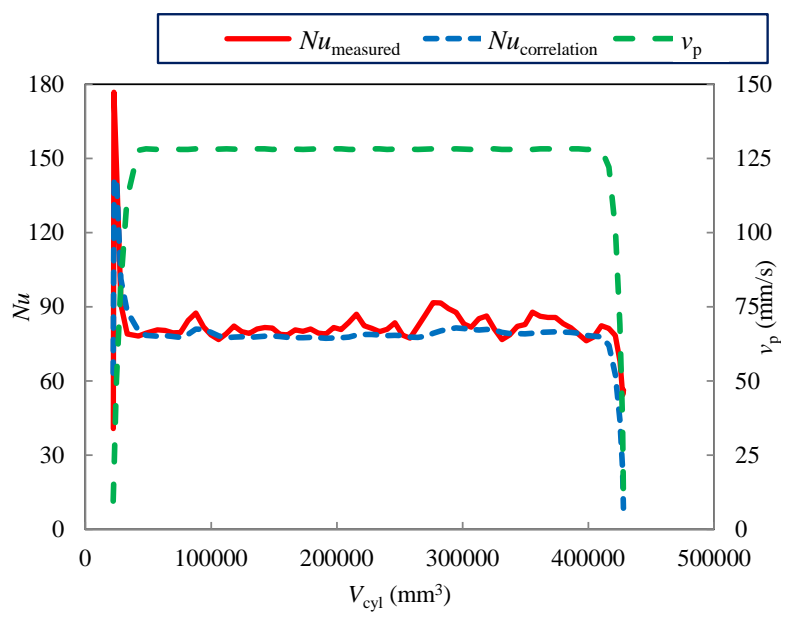

Fig. 2 Measured and predicted $N u$ for water without intake and exhaust processes, $T_{0}=100{ }^{\circ} \mathrm{C}, D_{\mathrm{p}}=55 \mathrm{~mm}$ and $v_{\mathrm{p}, \max }$ $=128 \mathrm{~mm} / \mathrm{s}$.

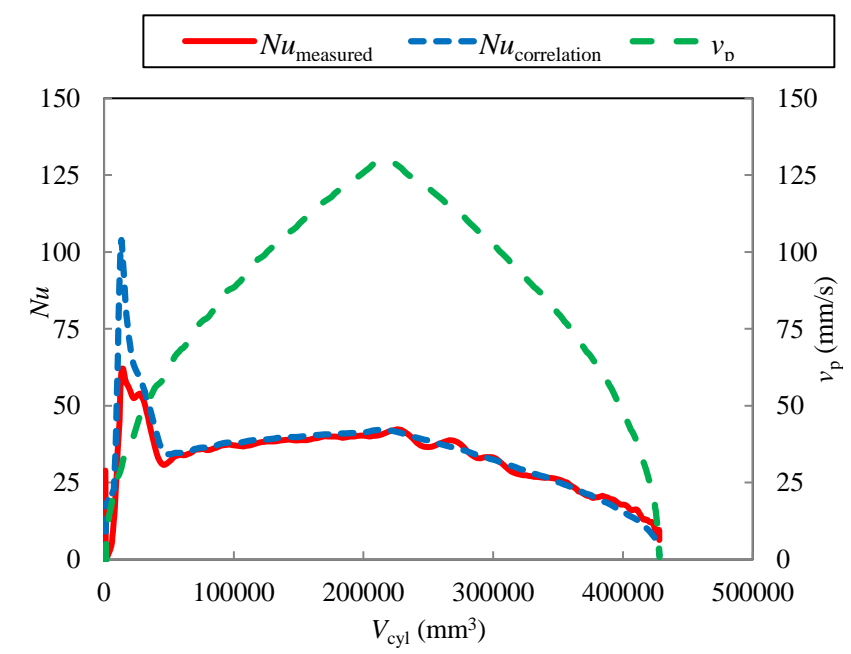

Fig. 3 Measured and predicted $N u$ for water with intake and exhaust processes, $T_{\mathrm{inj}}=100{ }^{\circ} \mathrm{C}, \varepsilon_{\mathrm{cut}, \mathrm{vol}}=3$ and $v_{\mathrm{p}, \max }$ $=131 \mathrm{~mm} / \mathrm{s}$.

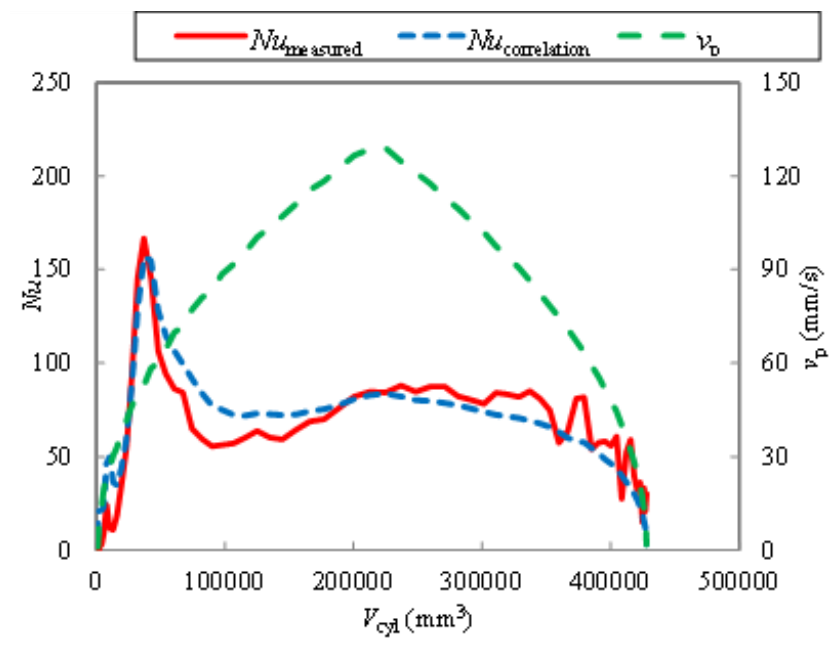

Fig. 4 Measured and predicted $\mathrm{Nu}$ for ethanol with intake and exhaust processes, $T_{\mathrm{inj}}=80{ }^{\circ} \mathrm{C}, \varepsilon_{\mathrm{cut}, \mathrm{vol}}=3$ and $v_{\mathrm{p}, \max }$ $=131 \mathrm{~mm} / \mathrm{s}$. 


\section{Model prediction}

\subsection{Calculation procedure}

The pressure change during two phase adiabatic expansion and indicated adiabatic efficiency are calculated as described below.

Conservation of liquid mass $m_{1}$, vapor mass $m_{\mathrm{v}}$ and injected liquid mass $m_{\mathrm{inj}}$ is expressed as Eq. (10). As the latent heat for phase change is supplied from the liquid, increase of vapor mass is expressed as Eq. (11). Equations (13) to (15) represent energy balance equations for the liquid phase, SUS bottom plate and the vapor phase, respectively. As the hot liquid is injected into the cold bottom plate, temporal change in liquid energy balances with the latent heat for vaporization, heat capacity loss and the injected energy as expressed in Eq. (12). This heat capacity loss is calculated using the heat transfer coefficient $h_{\text {Sus }}$ between the bottom plate and the liquid, which is experimentally obtained from our previous study $[17,18]$. In the energy balance equation for the bottom stainless plate, Eq. (14), the initial bottom stainless plate temperature is assumed to be equal to the saturated temperature at the cylinder pressure just before expansion. As vapor temperature $T_{\mathrm{v}}$, and interface temperature $T_{\text {int }}$, are assumed to be equal to the saturation temperature $T_{\text {sat }}$, the internal energy of the vapor phase balances with the generated internal energy at the interface and the indicated work, as shown in Eq. (14). Internal energy $u_{\mathrm{v}}$ and pressure $p_{\mathrm{v}}$ of the saturated vapor are expressed as a function of vapor temperature $T_{\mathrm{v}}$ and calculated using REFPROP [25]. From Eqs. (10) - (14), five unknown variables, i.e. liquid mass $m_{\mathrm{l}}$, vapor mass $m_{\mathrm{v}}$, liquid phase temperature $T_{1}$, bottom plate temperature $T_{\text {SUS }}$ and vapor phase temperature $T_{\mathrm{v}}$ are solved. Indicated adiabatic efficiency is calculated by taking the ratio of the predicted pressure change to the pressure change in the quasistatic expansion $[17,18]$. We verified the dependence on time step $\Delta t$, and set small enough $\Delta t$ so that the results are independent on the time step.

$$
\begin{gathered}
\frac{\mathrm{d} m_{\mathrm{l}}}{\mathrm{d} t}+\frac{\mathrm{d} m_{\mathrm{v}}}{\mathrm{d} t}=\frac{\mathrm{d} m_{\text {inj }}}{\mathrm{d} t} \\
\frac{\mathrm{d} m_{\mathrm{v}}}{\mathrm{d} t}=\frac{S_{\mathrm{p}} h_{\text {int }}\left(T_{1}-T_{\mathrm{v}}\right)}{L} \\
C p_{1} \frac{\mathrm{d}\left(m_{\mathrm{l}} T_{\mathrm{l}}\right)}{\mathrm{d} t}=\frac{\mathrm{d} m_{l}}{\mathrm{~d} t} L+A h_{\mathrm{SUS}}\left(T_{\mathrm{SUS}}-T_{\mathrm{l}}\right) \\
-\frac{\mathrm{d} m_{\text {inj }}}{\mathrm{d} t} C p_{\mathrm{l}}\left(T_{\text {inj }}-T_{\mathrm{l}}\right) \\
\frac{\mathrm{d}\left(m_{\mathrm{v}} u_{\mathrm{v}}\right)}{\mathrm{d} t}=u_{\mathrm{v}} \frac{\mathrm{d} m_{\mathrm{v}}}{\mathrm{d} t}-p_{\mathrm{v}} \frac{\mathrm{d} V_{\text {cyl }}}{\mathrm{d} t} \\
=\frac{S_{\mathrm{p}} h_{\mathrm{int}}\left(T_{1}-T_{\mathrm{v}}\right)}{L} u_{\mathrm{v}}-p_{\mathrm{v}} \frac{\mathrm{d} V_{\text {cyl }}}{\mathrm{d} t}
\end{gathered}
$$

\subsection{Model predictions and experimental results}

Figure 5 shows the measured and predicted $P-V$ diagrams for water without intake and exhaust processes. The model predicts well the initial pressure decrease at the early stage of expansion and its gradual decrease during the 
expansion process. The pressure becomes lower as the piston speed is increased, which is also predicted well by the model. Figure 6 shows the measured and predicted evaporation mass flow rates. Evaporation mass flow rate increases immediately and gradually decrease during the expansion process. As can be seen from the figure, the model prediction matches well with the experimental results. Figure 7 shows the measured and predicted indicated adiabatic efficiencies. The indicated adiabatic efficiency decreases with the piston speed, which is again well predicted by the model. It is emphasized that the indicated adiabatic efficiency shows a very high value $\left(\eta_{\text {ad }}>80 \%\right)$ for the present experimental condition.

Figure 8 shows the measured and predicted $P-V$ diagrams for water with intake and exhaust processes. The initial pressure increase and decrease is considered to be a consequence of the heat capacity loss, which is well predicted by the present model. The pressure is higher for faster piston speed, which can be attributed to the reduction of heat capacity loss to the cooled bottom plate [18]. Figure 9 shows the measured and predicted evaporation mass flow rates. The predicted evaporation mass flow rate also matches well with the experimental result. Figure 10 shows the measured and predicted adiabatic efficiencies with intake and exhaust processes. Indicated adiabatic efficiency increases as the piston velocity is increased, and it reaches an asymptotic value of about $84 \%$. This trend is again attributed to the reduction of heat capacity loss at high frequency. The present model predicts the indicated adiabatic efficiency within about $5 \%$ accuracy, which indicates that the degradation of the indicated adiabatic efficiency is mainly due to the insufficient heat transfer from the liquid bulk to the interface. At the beginning of the expansion process, the temperature difference of the liquid bulk and the saturation becomes large, and the inner pressure is decreased. After that the evaporation mass flow rate increases immediately and pressure decrease becomes moderate. In Eq. (6), the Nusselt number $N u$ depends on Bond number as $B o^{-0.4}$. Bond number $B o$ is determined from $J a$ in Eq. (8), which is calculated from the temperature difference as shown in Eq. (9). Therefore, if the temperature difference becomes large, $J a$ becomes large which leads to the suppression of $\mathrm{Nu}$.

For the actual trilateral cycle, the operating pressure and expansion ratio become high with the increase of heat source temperature [2]. In order to reduce expansion ratio and operating pressure, partially evaporated working fluid can be introduced to the two-phase expander. In the present study, non-equilibrium loss is mainly attributed to the nonuniformity of the temperature distribution in the liquid phase. Therefore, it is considered that the non-equilibrium loss may be reduced if the ratio of liquid phase at the expander inlet is reduced, which will lead to an increase of adiabatic efficiency. In addition, the liquid phase can be agitated by the vapor bubbles and the non-equilibrium loss should be further reduced. The effects of the amount of vapor phase at the expander inlet on the non-equilibrium loss and on the adiabatic efficiency will be further evaluated as a future work. 


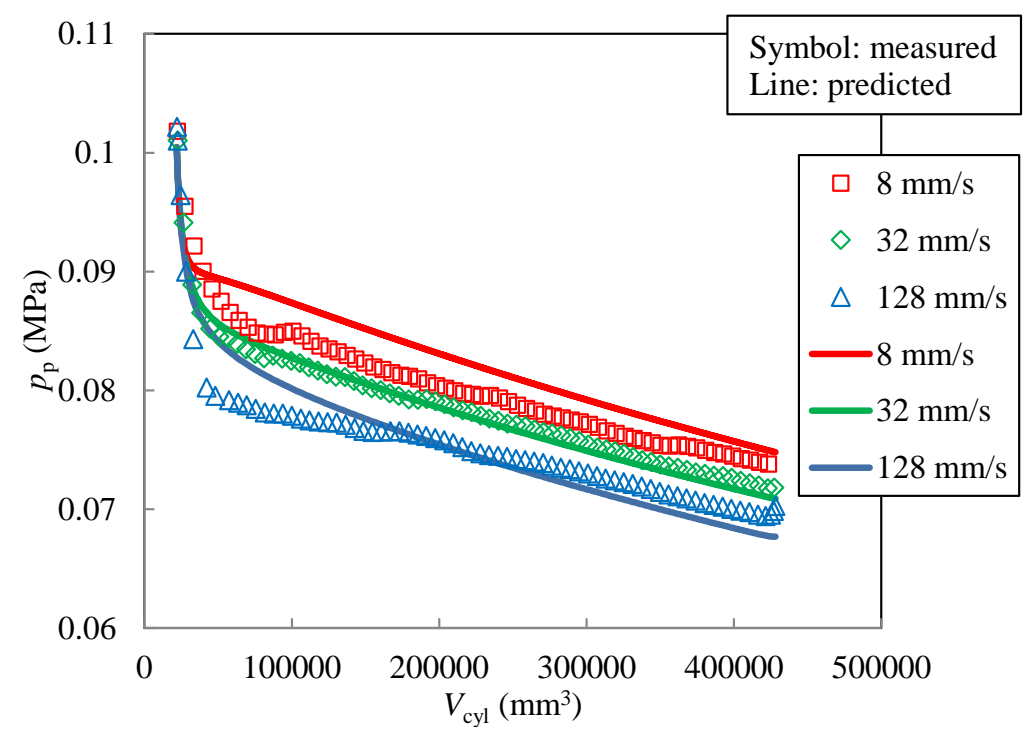

Fig. 5 Measured and predicted $P-V$ diagrams for water without intake and exhaust processes, $T_{0}=100{ }^{\circ} \mathrm{C}, D_{\mathrm{p}}=55 \mathrm{~mm}$ and $v_{\mathrm{p}, \max }$ $=8,32,128 \mathrm{~mm} / \mathrm{s}$.

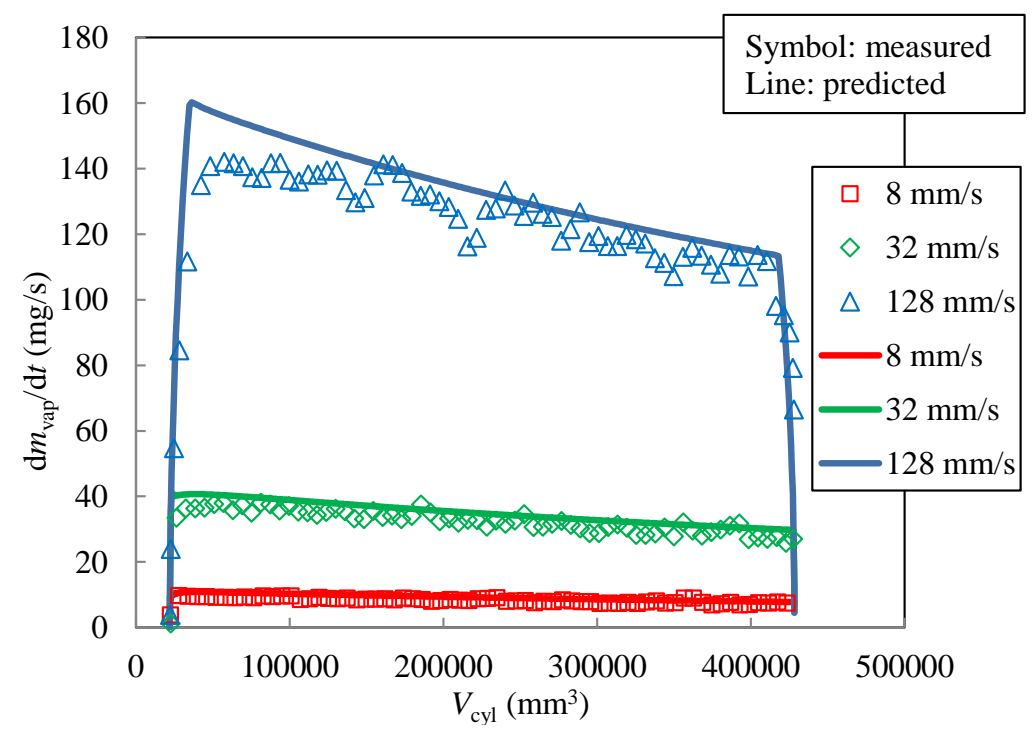

Fig. 6 Measured and predicted evaporation mass flow rates for water without intake and exhaust processes, $T_{0}=100{ }^{\circ} \mathrm{C}, D_{\mathrm{p}}=55 \mathrm{~mm}$ and $v_{\mathrm{p}, \max }=8,32,128 \mathrm{~mm} / \mathrm{s}$. 


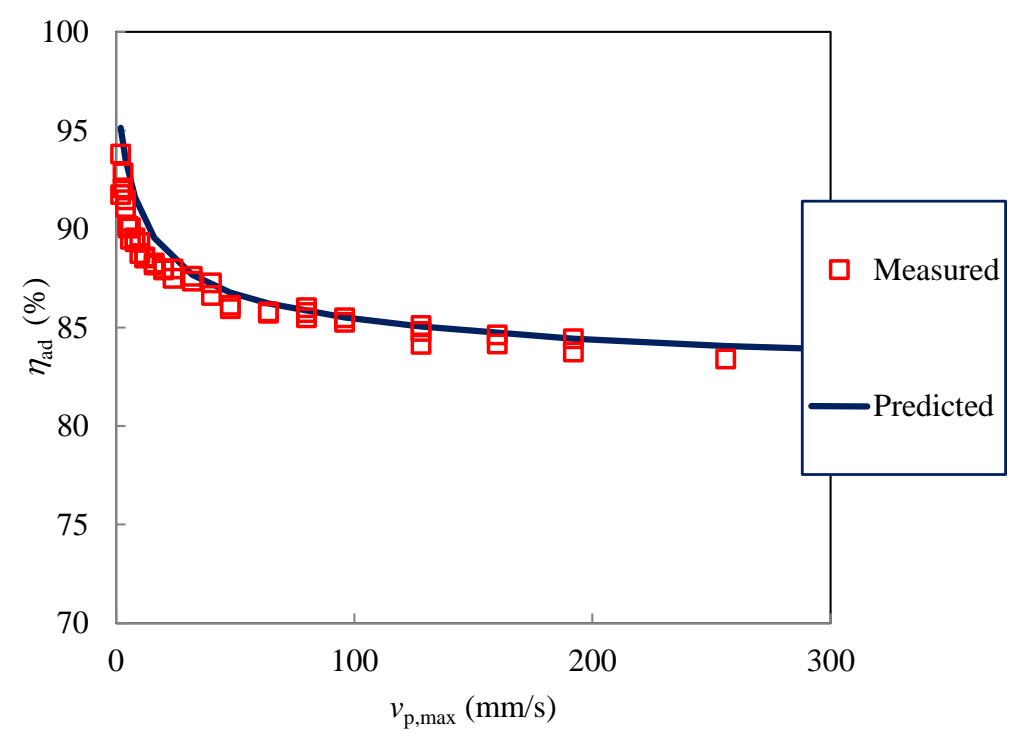

Fig. 7 Measured and predicted indicated adiabatic efficiencies for water without intake and exhaust processes, $T_{0}=100{ }^{\circ} \mathrm{C}, D_{\mathrm{p}}=55$ $\mathrm{mm}$.

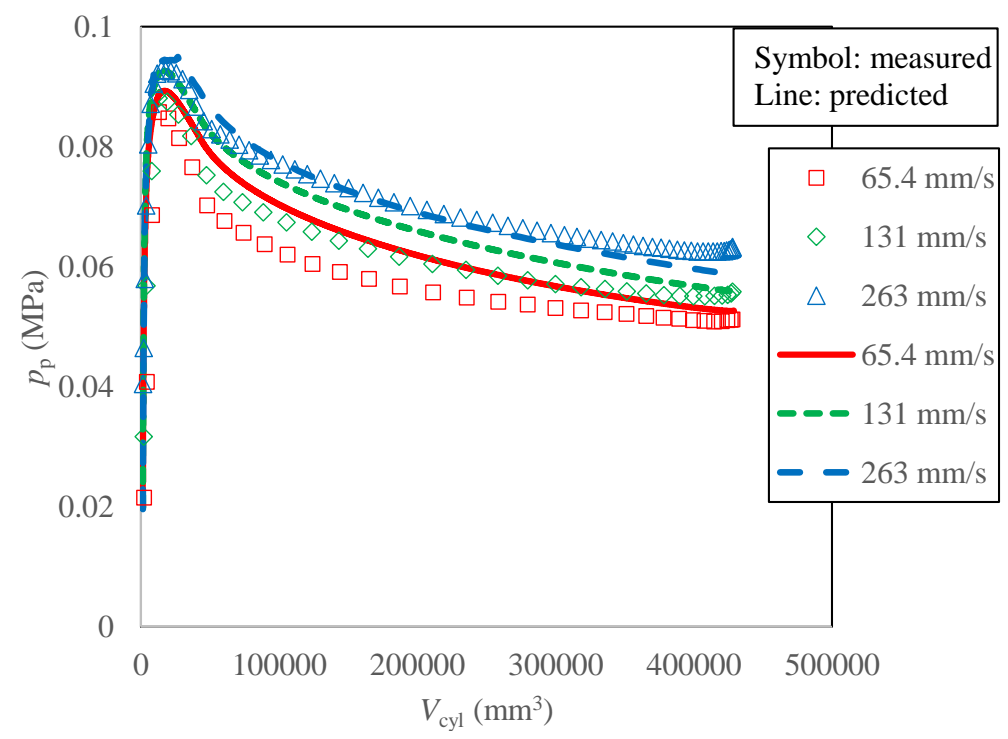

Fig. 8 Measured and predicted $P-V$ diagrams for water with intake and exhaust processes, $T_{\text {inj }}=100{ }^{\circ} \mathrm{C}, \varepsilon_{\text {cut }, \text { vol }}=3$ and $v_{\mathrm{p}, \max }=65.4$, $131,263 \mathrm{~mm} / \mathrm{s}$. 


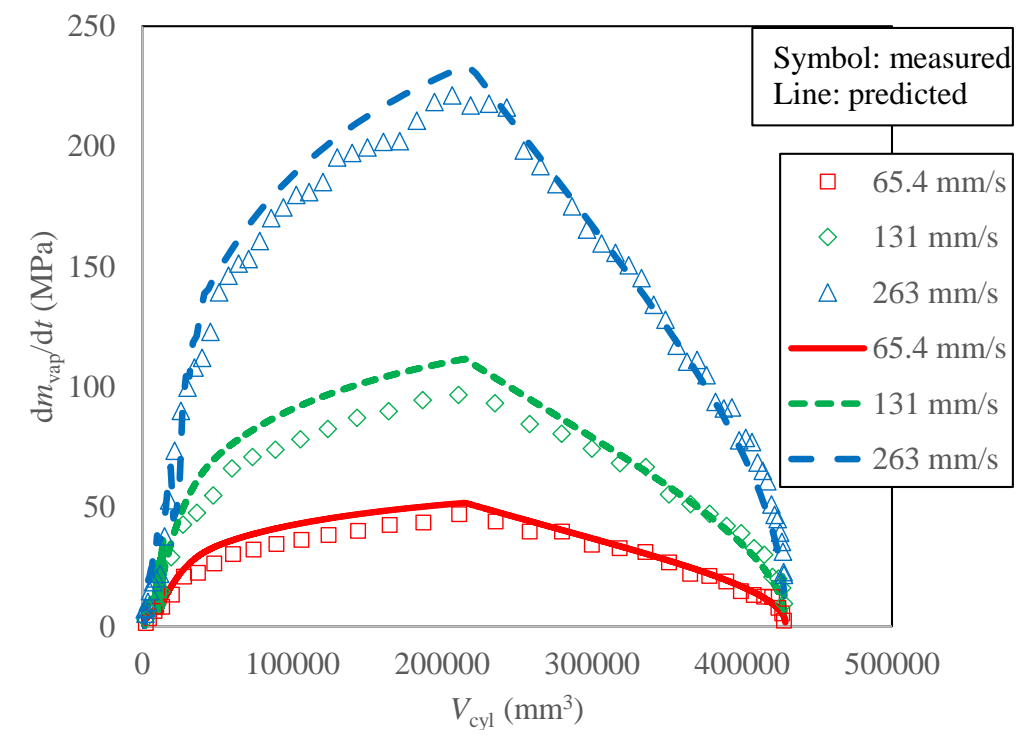

Fig. 9 Measured and predicted evaporation mass rates for water with intake and exhaust processes, $T_{\mathrm{inj}}=100{ }^{\circ} \mathrm{C}, \varepsilon_{\mathrm{cut}, \mathrm{vol}}=3$ and $v_{\mathrm{p}, \max }$ $=65.4,131,263 \mathrm{~mm} / \mathrm{s}$.

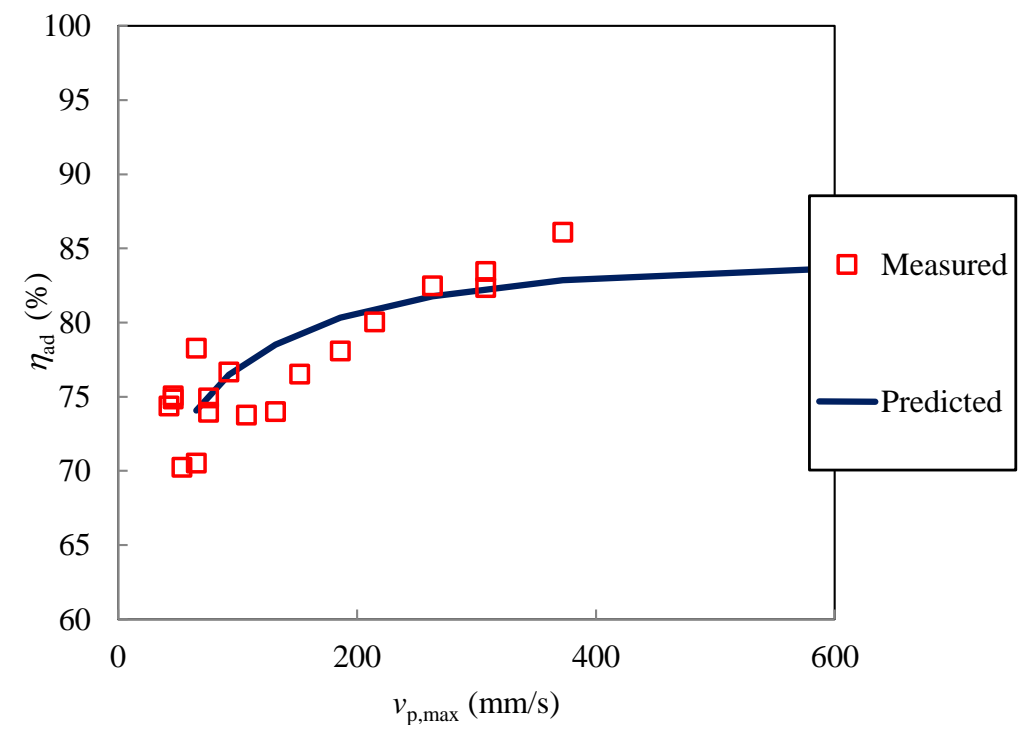

Fig. 10 Measured and predicted indicated adiabatic efficiencies for water with intake and exhaust processes, $T_{\text {inj }}=100{ }^{\circ} \mathrm{C}, \varepsilon_{\text {cut }, \text { vol }}=3$.

\section{Conclusion}

A numerical model to predict two-phase adiabatic expansion in a reciprocating cylinder is proposed. Heat transfer coefficient from the liquid bulk to the gas-liquid interface is correlated as a Nusselt number which is expressed as a function of Prandtl, Reynolds and Bond numbers. Using the correlated Nusselt number, the energy balance equations are solved to predict the pressure change and the indicated adiabatic efficiency during two phase adiabatic expansion. It is assumed that two phase adiabatic vaporization in a cylinder is considered to be mainly dominated by the heat transfer from the bulk liquid to the gas-liquid interface. The present model can predict the pressure-change and indicated adiabatic efficiency in two-phase expansion well with and without intake and exhaust processes. The model predicts the indicated adiabatic efficiency within about $5 \%$ accuracy, which indicates that the degradation of the indicated adiabatic efficiency is mainly 
due to the insufficient heat transfer from the liquid bulk to the interface.

\section{Acknowledgements}

This work has been partly supported by the Japan Science and Technology Agency (JST). The authors gratefully acknowledge them for the financial support.

\section{References}

1. J. Fischer, Comparison of trilateral cycles and organic Rankine cycles, Energy 36 (2011), pp. 6208 - 6219.

2. H. Kanno \& N. Shikazono, Thermodynamic Simulations of Rankine, Trilateral and Supercritical Cycles for Hot Water and Exhaust Gas Heat Recovery, Mechanical Engineering Journal, 1 (5), p. TEP0046 (2014).

3. C. Zamfirescu \& I. Dincer, Thermodynamic analysis of a novel ammonia-water trilateral Rankine cycle, Thermochimica Acta 477 (2008), pp. 7 - 15.

4. T. Ho, S. S. Mao \& R. Greif, Comparison of the Organic Flash Cycle (OFC) to other advanced vapor cycles for intermediate and high temperature waste heat reclamation and solar thermal energy, Energy 42 (2012), pp. 213 - 223.

5. N. A. Lai \& J. Fischer, Efficiencies of power flash cycles, Energy 44 (2012), pp. 1017 - 1027.

6. I.K. Smith, Development of the trilateral flash cycle system. 1. Fundamental considerations, Journal of Power and Energy 207 (1993), pp. 179-194.

7. I.K. Smith \& R.P.M. Dasilva, Development of the trilateral flash cycle system. 2. Increasing power output with working fluids mixtures, Journal of Power and Energy 208 (1994), pp. 135-144.

8. I.K. Smith, N. Stosic \& C.A. Aldis, Development of the trilateral flash cycle system. 3. The design of high-efficiency two-phase screw ex panders, Journal of Power and Energy 210 (1996), pp. 75-93.

9. M. Oreijah, A. Date \& A. Akbarzadaha, Comparison between Rankine Cycle and Trilateral Cycle in Binary System for Power Generation, Applied Mechanics and Materials 464 (2014), pp 151-155.

10. H.Ohman \& P. Lundqvist, Experimental investigation of a Lysholm Turbine operating with superheated, saturated and 2 - phase inlet conditions, Applied Thermal Engineering 50 (2013), pp. 1211 - 1218.

11. H.Ohman \& P. Lundqvist, Screw Expanders in ORC Applications, Review and a New Perspective, Proc. 3rd International Seminar on ORC Power Systems, Brussels, Belgium, October 12-14, asme-orc 201545 (2015).

12. J. Bao \& L. Zhao, A review of working fluid and expander selections for organic Rankine cycle, Renewable and sustainable Energy Reviews 24 (2013), pp. 325 - 342.

13. J. Yan, D. Zhang, D. Chong, G. Wang, L. Li, Experimental study on static/circulatory flash evaporation, International Journal of Heat and Mass Transfer 53 (2010), pp 5528-5535.

14. D. Zhang, D. Chong, J. Yan, Y. Zhang, Study on steam-carrying effect in static flash evaporation, International Journal of Heat and Mass Transfer 55 (2012), pp 4487-4497.

15. D. Saury, S. Harmand, M. Siroux, Flash evaporation from a water pool:Influence of the liquid height and of the depressurization rate, International Journal of Thermal Sciences 44 (2005), pp 953-965.

16. M. Steffen, M. Lofffler \& K. Schaber, Efficiency of a new Triangle Cycle with flash evaporation in a piston engine, Energy, Vol.57 (2013), pp. 295-307.

17. H. Kanno and N. Shikazono, Experimental and Modeling Study on Adiabatic Two-phase Expansion in a Cylinder, International Journal of Heat and Mass Transfer, 86 (2015), pp. 755-763. 
18. H. Kanno and N. Shikazono, Experimental Study on Two-phase Adiabatic Expansion in a Reciprocating Expander with Intake and Exhaust Processes, submitted to International Journal of Heat and Mass Transfer (2016).

19. The Japan Society of Mechanical Engineers, Heat Transfer, JSME Textbook Serie, MARUZEN-YUSHODO Company.

20. I.L.Piori, W. Rohsenow, S.S.Doerffer, Nucleate pool-boiling heat transfer. 1: review of parametric effects of boiling surface, International Journal of Heat and Mass Transfer, Vol. 47 (2004), pp5033 - 5044.

21. I.L.Piori, W. Rohsenow, S.S.Doerffer, Nucleate pool-boiling heat transfer. 2: assessment of prediction methods, International Journal of Heat and Mass Transfer, Vol. 47 (2004), pp5045- 5057.

22. R.Cole, J. M. Papazian, W.R.Wilcox, Bubble departure radii at solidification interfaces, International Journal of Heat Mass Transfer. Vol.23 (1980), pp 219-224.

23. S. Hamzekhani, M. Maniavi Falahieh, A. Akbari, Bubble departure diameter in nucleate pool boiling at saturation: Pure liquids and binary mixtures, International journal of refrigeration 46 (2014) pp 50-58.

24. J. Kim, M.H. Kim, On the departure behaviors of bubble at nucleate pool boiling, International Journal of Multiphase Flow, Vol. 32 (2006), pp 1269-1286.

25. E.W. Lemmon, M.L. Huber \& M.O. McLinden, NIST standard reference database 23: reference fluid thermodynamic and transport properties REFPROP version 9.0. Gaithersburg: National Institute of Standards and Technology, Standard Reference Data Program; 2010. 